\title{
Production Costs and Markets for Pellet Chips: Case Studies in Northern Sweden
}

\author{
Gunnar Eriksson, ${ }^{1}$ Dimitris Athanassiadis, ${ }^{1}$ Dan Bergström, ${ }^{1}$ \\ Tomas Nordfjell, ${ }^{1}$ and Urban Bergsten ${ }^{2}$ \\ ${ }^{1}$ Department of Forest Resource Management, Swedish University of Agricultural Sciences, 90183 Umeå, Sweden \\ ${ }^{2}$ Department of Forest Ecology and Management, Swedish University of Agricultural Sciences, 90183 Umeå, Sweden
}

Correspondence should be addressed to Gunnar Eriksson, gunnar.eriksson@slu.se

Received 1 December 2011; Revised 13 March 2012; Accepted 27 March 2012

Academic Editor: David B. DeVallance

Copyright (C) 2012 Gunnar Eriksson et al. This is an open access article distributed under the Creative Commons Attribution License, which permits unrestricted use, distribution, and reproduction in any medium, provided the original work is properly cited.

\begin{abstract}
Increasing use of woody fuels requires that nontraditional types of raw materials are exploited, including logging residues and small-diameter trees. Although medium-scale combustors often use pellets, they could conceivably use dried chips of sufficiently narrow size distribution (henceforth pellet chips). The influence of the following factors on the relative cost-effectiveness of producing pellets and pellet chips was investigated for three plant sites in northern Sweden: (1) harvesting and transporting of forest residues; (2) the potential of existing energy plants to supply drying heat in periods of capacity surplus; (3) the distance to potential end-users. Data from the national forest inventory were used to estimate raw material costs. The resulting production costs were 144-176 \$ per oven-dry tonnes (OD t) for pellets $\left(27.4-33.5 \$ \mathrm{MWh}^{-1}\right)$ and $143-173 \$ \mathrm{OD} \mathrm{t}^{-1}\left(27.2-33.0 \$ \mathrm{MWh}^{-1}\right)$ for pellet chips, with harvesting, forwarding, chipping, and transporting of logging residues to the sites amounting to 114 $122 \$ \mathrm{OD} \mathrm{t}^{-1}\left(21.7-23.2 \$ \mathrm{MWh}^{-1}\right)$ for both fuels. Even though the differences in production costs were minor, the production of pellet chips requires significantly less electricity input per OD t of produced fuel. For cost reductions improved methods for wood fuel procurement, compacting and transporting of chips, small-scale low-temperature drying and foliage and bark separation are needed.
\end{abstract}

\section{Introduction}

Interest in renewable energy has been spurred by public awareness of climate change, international obligations to decrease greenhouse gas emissions, and the scarcity of fossil fuels. Consequently, woody fuels are becoming increasingly popular sources of heat and power worldwide. They are used in new biofuel-based heat and power plants, converted-coaland oil-based boilers, and in systems based on cogeneration with coal [1].

In Europe and North America, woody fuels have to some extent replaced oil and electricity for small-scale residential heating and for medium-scale combustors supplying users such as small district heating networks, schools, and industrial facilities. Most of this is pellets from dried woody biomass (which are also used in large-scale power plants because densification facilitates handling and long-range transport), but chips are also used. The pellet consumption in the small- and medium-scale markets in these regions was in 200512.5 to 15 TWh [2]. In Sweden, 3.9 TWh of the pellets was used for small-scale residential heating in 2010 and about 0.4 TWh was used in medium-scale district heating (annual heat deliveries below $10 \mathrm{GWh}$ ) [3, 4]. Further, about 0.5 TWh of chips was used in small-scale residential heating [5] and about 0.3 TWh (possibly including crushed and hogged woody fuel) in the smallest district heating plant [4].

The availability of woody biomass depends on local and regional conditions. However, energy plants in different regions face similar challenges regarding forest biomass procurement, refining, and combustion technology. In order for fuel pellet production to keep pace with the expected increases in demand, it will be necessary to exploit nontraditional raw materials. While there is still a surplus of saw mill residues in some markets, for example, Canada, Latin 
America, and parts of India [6-8], there is definitely a shortage in Sweden. One such source of nontraditional raw biomass is the Canadian stands affected by the mountain pine beetle, which have little use except as fuel [9]. In the southern and western USA, thinning operations have been suggested as a wildfire prevention measure, and it has been proposed that material from the extracted trees could be used for power production $[10,11]$.

Ash-forming elements in the fuel, which are mostly from branches, bark, and foliage or from contamination [12, 13], determine the formation of potentially health-threatening particles [14] and the risk of ash-related operational problems [15]. While high-quality biomass generate relatively low particle emissions even when burned in small-scale combustors, more ash-rich fuels require combustors fitted with flue gas cleaning systems such as multicyclones, which are rare in combustors for single-family houses. The strictest standard for fuel pellets, SS 187120, requires ash contents below $0.7 \%$ wt.d.s. [16]; fuels meeting this requirement are typically made from stemwood-derived raw materials such as saw dust and planer shavings.

In Fennoscandia, high-quality round wood is highly utilized by sawmills and the pulp industry, so the energy sector is increasingly reliant on stumps, logging residues, smalldiameter trees, and low-quality round wood. Despite their bark content, energy wood (which is of lower quality than pulpwood or derived from stands that are further from sawmills) and small wood from early thinnings both represent fuel assortments that could potentially result in fuels with ash contents below $0.7 \%$. Conversely, fuels derived from logging residues (whose ash concentrations range from 1 to $8 \%$ wt.d.s., depending on how they are handled), are best used in medium-scale combustors with particle filtering systems [17-20]. Annually, 3.2-4.2 million oven-dry tonnes $(\mathrm{OD} \mathrm{t})$ of potentially harvestable logging residues and stumps are generated during regeneration fellings in Sweden [21]. For comparative purposes, the current annual consumption of logging residues in Sweden is approximately 2 million OD t [22].

Common types of small-to-medium-scale combustors (below $10 \mathrm{MWth}$ ) for chips are (1) precombustors/preovens with separate secondary combustors, (2) grates, or (3) stoker burners $[23,24]$. They are adapted to a certain range of moisture content (MC) [25]. To cope with moist chips, insulated precombustors/primary combustors and air preheating can be used $[23,26]$. Grate areas must be $120 \%$ larger when the MC increases from 30 to $60 \%$ and combustor volume must be larger. Stoker burners are more sensitive to high MC, compared to precombustors and grate combustors. Smallerscale combustors are more sensitive, as the combustion is concentrated to a smaller area with less fuel [24]. The cost of adaptation to moist fuels is a serious disadvantage, and dried fuels are therefore often preferred at small-to-medium scale [27]. Variations in fuel chip particle size (causing fluctuations in fuel feeding rate and in MC) cause serious control problems in small-to-medium-scale chip combustion [27, 28]. Particle sizes above $50 \mathrm{~mm}$ may require more complex fuel feeding systems than augers like vibroconveyors or troughed chain conveyors [24].
Small-scale combustion thus requires fuel of a higher quality than that used on larger scales. Pellets are made from dried biomass and have much less variations in particle size compared to conventional wood chips. Conventional chipping of woody biomass followed by grinding and pelletizing may not be the most cost-effective way of preparing high-quality fuel. Instead, it may be better to comminute, assort, and dry the biomass in a way that produces wood chips whose combustion properties are more comparable to those of pellets (Table 1). Sieving and drying have been suggested as ways to upgrade chips [27]. Optimal chipping could simplify upgrading downstream in the product chain. Factors that determine the particle size distribution of chips include chipper type, tree species, and blade wear, and it can also be influenced by the choice of chipping screen [29-31].

Dried wood chips with limited variation in particle size which have been upgraded for the small- and medium-scale market have been referred to as "pellet chips" [30], a term which will henceforth be used as there is no established term to distinguish them from more moist chips with wider size distributions. Pellet chips could either be used directly in less sensitive small- and medium-scale combustors (replacing pellets) or as a raw material for producing fuel pellets to be consumed in more distant markets.

The cost of drying contributes significantly to the overall cost of production and is considerably lower (per unit dried mass) on larger scales because the investment usually increases with scale according to a power law, with an exponent of less than 1 [32]. In temperate climates, heat plants and combined heat and power plants usually have excess combustion capacity at certain times of the year due to seasonal variation in temperature. This excess capacity could be used to dry fuel and thereby obtain additional revenue from existing investments.

There are differences in size distribution and density between pellets and pellet chips, resulting in differences in terms of their production, transport, storage, and combustion properties [33]. Some stages of the production processes for pellets and pellet chips are very similar, such as raw material handling and storage, drying, and the loading of the product. Others are required only for pellet production, that is, grinding, pelletizing, and cooling. Naturally, for various practical and economic reasons, only a fraction of the potential market will be available to a new supplier. However, provided that a fuel can be comminuted, dried, and transported at a competitive cost and is suitable for use in existing combustors, there exists a market opportunity. For any site, the profitability of fuel production will be determined by the raw material cost, the production cost (especially the cost of drying and the availability of excess heat or combustion capacity), and by the distribution of potential users. When selecting a suitable site, the combined effects of these factors must be considered.

\section{Objectives}

The purpose of the study reported herein was to assess the use of logging residues as a dried fuel of narrow particle size distribution (pellet chips) in northern Sweden. More 
TABle 1: Properties of pellets and chips according to standard [16] and the Fuel Handbook [55]. MC: moisture content, LHV: lower heating value.

\begin{tabular}{|c|c|c|}
\hline & Pellets $(8 \mathrm{~mm})$ & Chips \\
\hline Particle size & $\begin{array}{c}\varnothing 8 \mathrm{~mm} \pm 0.1 \mathrm{~mm}, 3.15 \mathrm{~mm} \leq \\
\text { Length } \leq 40 \mathrm{~mm}\end{array}$ & $3.15 \mathrm{~mm} \leq$ Length $\leq 6 \mathrm{~mm}$ \\
\hline Fines & $\leq 3 \mathrm{~mm}, 12 \% \mathrm{wt}$ & $\leq 3.15 \mathrm{~mm}, 1 \% \mathrm{wt}$ \\
\hline MC, \% wt (as delivered) & $<10$ & $<10$ \\
\hline Ash content, \% wt (dry basis) & $<0.7$ & $<0.7$ \\
\hline $\begin{array}{l}\text { Volatile content, }{ }^{*} \% \text { wt (dry } \\
\text { basis) }\end{array}$ & 81 & 84 \\
\hline $\mathrm{LHV}, \mathrm{MJ} \mathrm{kg}^{-1}$ (at $10 \% \mathrm{MC}$ ) & 17.0 & 17.0 \\
\hline $\mathrm{C}$ & $49.6-53.13$ & $49.6-53.13$ \\
\hline $\mathrm{H}$ & $5.8-6.2$ & $5.8-6.2$ \\
\hline $\mathrm{O}$ & $38.1-40.8$ & $38.1-40.8$ \\
\hline $\mathrm{N}$ & $0.3-0.8$ & $0.3-0.8$ \\
\hline S & $0.04-0.06$ & $0.04-0.06$ \\
\hline $\mathrm{Cl}$ & $0.02-0.03$ & $0.02-0.03$ \\
\hline Bulk density $\left(\mathrm{t} \cdot \mathrm{m}^{-3}\right.$ solid $)$ & $\begin{array}{l}\quad 0.550-0.700 \\
\text { Assumed in this study: } 0.720 \\
\text { (at } 5.5 \% \mathrm{MC})[33]\end{array}$ & $\begin{array}{c}\text { Not specified by standard, } 0.220 \\
\text { (at 26\% MC) assumed in this } \\
\text { study [33] }\end{array}$ \\
\hline
\end{tabular}

* For wood fuel.

specifically, the objective was to determine how the following factors influence the relative cost-effectiveness of producing pellets and pellet chips:

(i) the cost of harvesting and transporting forest residues;

(ii) the nature of the existing energy plants (and their potential for pellet production), their capacity, and production costs;

(iii) the distance to potential markets (end-users) and transport costs.

\section{Material and Methods}

3.1. Study Design. The study focused on the production of dried fuel from logging residues and the associated supply costs. The influence of the choice of location and the choice of product on economic viability was assessed. Three different locations in Sweden of a hypothetical fuel production facility were considered. It was assumed that the harvested biomass would be chipped at the landing and transported to a central site for further processing, with the chips being dried on site at the production facility. It was further assumed that the chip particle size distribution would be sufficiently homogeneous for the dried chips to be combusted in a reasonable proportion of existing pellet-fueled small- and medium-scale combustors, thus qualifying them as "pellet chips." After drying, the chips were either ground and pelletized before being stored and transported to users or stored directly without further processing. The following alternative locations in the county of Västerbotten, northern Sweden, were compared: (1) Vännäs (a coastal location), (2) Lycksele (in the interior of the region), and (3) Vilhelmina (close to a mountainous region) (Figure 1). The population densities of the municipalities of Lycksele, Vilhelmina, and Vännäs were $2.2,0.88$, and 16 inhabitants per $\mathrm{km}^{2}$, respectively. Vännäs is located in the more densely populated coastal region, $30 \mathrm{~km}$ away from the region largest town (Umeå, with a population of 114000).

Raw material costs were estimated from National Forest Inventory (NFI) data in conjunction with specific information about the three locations. The production costs for pellets and pellet chips were estimated, using data on investments and operating costs from the literature [34] and considering opportunities for integration with existing energy plants at the proposed sites (Sections 3.2-3.8). Potential markets for the fuels produced and costs for transport from the three sites were estimated based on public statistics for the region (Section 3.9).

A sensitivity analysis of the total supply costs was performed in which the following parameters were varied by $\pm 50 \%$ : raw material cost, electricity cost/electricity revenues, production cost, and transport costs. Production capacity was varied by $\pm 15 \%$.

3.2. Plant Sites. Sites for the hypothetical plants were chosen next to district heating plants at all locations. The Lycksele plant was a combined heat and power plant while those at Vilhelmina and Vännäs were district heating plants only. Due to seasonal variation in demand, some of the plants had excess combustion capacity that was available during some parts of the year and could be used to generate heat for drying biomass fuel (Section 3.4). The Lycksele plant had an unusually high annual excess heat production capacity of 25 GWh because a nearby sawmill supplied by the plant had recently been shut down [35].

The Vilhelmina heat plant had a combustion capacity of $20 \mathrm{MW}$ and delivered $58.5 \mathrm{GWh}$ of heat annually. Its 


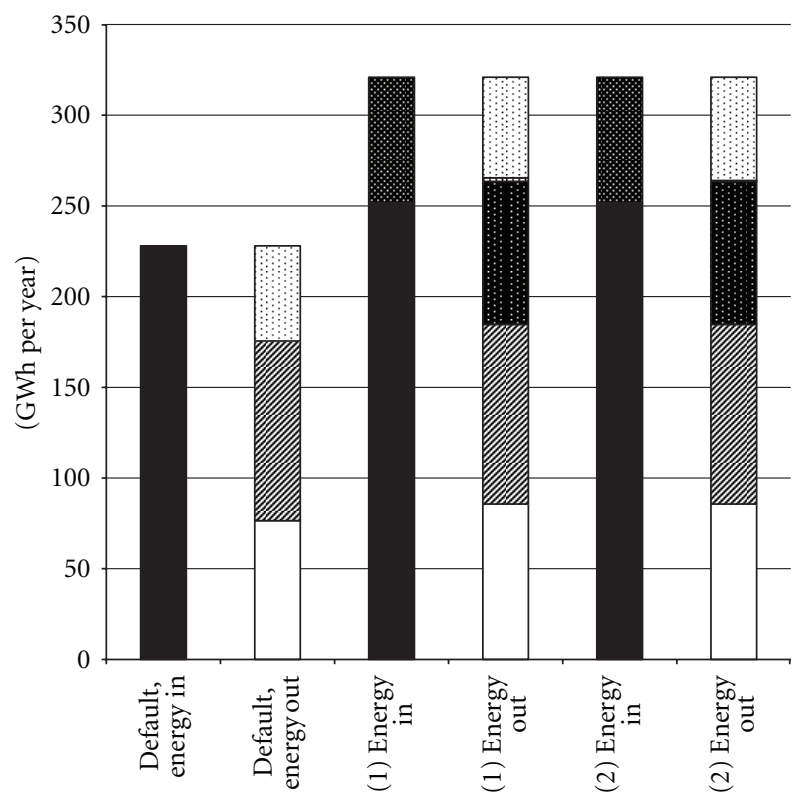

(a)

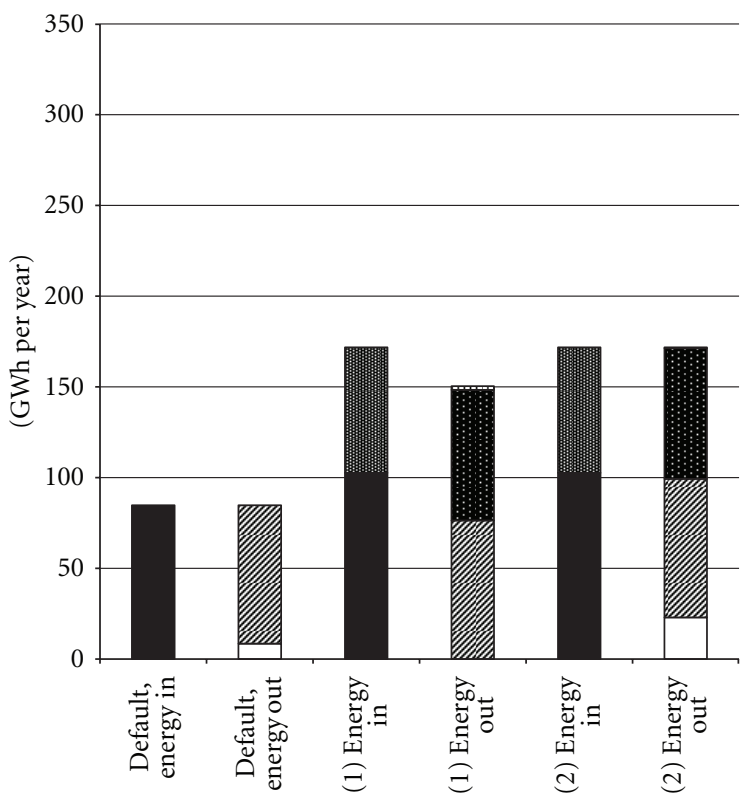

(b)

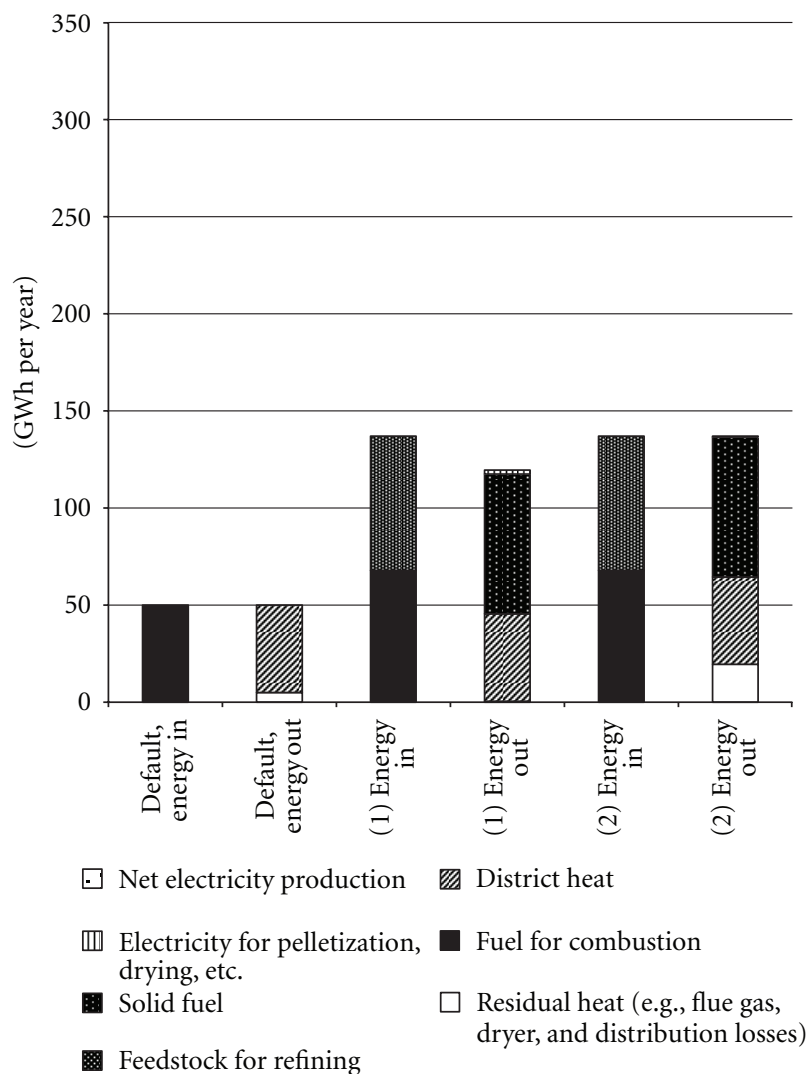

(c)

Figure 1: Energy balances for the three plant sites_Lycksele (a), Vilhemina (b), and Vännäs (c)—under the current regime (default), for pellet production (1) and for pellet chip production (2). 
TABLE 2: Methods for calculating the marginal costs for extraction and delivery of logging residues for the plant sites.

\begin{tabular}{lcc}
\hline Cost & Parameter used to calculate cost & Method of calculation $\left(\$\right.$ OD t $\left.^{-1}\right)$ \\
\hline Forwarding to roadside, $C_{1}$ & Forwarding distance $d_{\mathrm{f}}(\mathrm{km})$ & $C_{1}=16.9+24.5 d_{\mathrm{f}}$ \\
Chipping at roadside, $C_{2}$ & & $C_{2}=21.7$ \\
Hauling to plant, $C_{3}$ & Hauling distance $d_{\mathrm{t}}(\mathrm{km})$ & $C_{3}=3.26+0.217 d_{\mathrm{t}}$ \\
Administrative costs, $C_{4}$ & & $C_{4}=9.61$ \\
Reimbursement to land owners, $C_{5}$ & & $C_{5}=22.5$ \\
Allocation costs for forwarders and chippers, $C_{6}$ & Number of machine allocations $\left(\mathrm{n}_{\mathrm{a}} \mathrm{OD} \mathrm{t}^{-1}\right)$ & $C_{6}=327 \mathrm{n}_{\mathrm{a}}$ \\
\hline
\end{tabular}

primary fuels were bark (37.2 GWh), shavings (28.7 GWh), and stemwood chips (7.0 GWh). Flue gas condensation was used at the plant.

The Vännäs plant had a $6 \mathrm{MW}$ boiler from which an additional 1-1.5 MW was recovered through flue gas condensation. A 3 MW boiler was used during the summer when heat demand was low. Various biomass fuels were used, including bark (33 GWh), stemwood chips (4.5 GWh), logging residues (0.5 GWh), and demolition wood. The maximum combined heat output of the plant boilers was insufficient to meet local demand when outdoor temperatures fell to $-13^{\circ} \mathrm{C}$ or below. In such cases, the shortfall was made up using oil or electric heaters, with capacities of $2.9 \mathrm{GWh}$ and 1.1 GWh, respectively $[4,36]$. The town of Umeå provided a considerable local market for biomass fuels.

3.3. Raw Material Supply. Available amounts of raw material and fuel (logging residues) in the vicinity of the plants and the cost for extracting and transporting them to each plant were estimated using data from the NFI, according to a previously described procedure [21]. The NFI sample plots around each plant were used to estimate the age, growing rates, and distribution among biocomponents of the trees and to forecast the areas due to regeneration fellings according to present practice. The amounts of logging residues that could accordingly be expected were calculated (nature protection areas, wet areas, waterlines, and slopes with inclinations above $19.6^{\circ}$ were not included, and from the remaining productive forest land, $40 \%$ of the logging residues were assumed to be left on the ground for practical reasons). It was further assumed that the raw material costs were dictated by the costs of extracting and transporting logging residues in the vicinity of the plants. The marginal cost $C\left(\$ O D t^{-1}\right)$ for the harvesting, processing, and transport of the logging residues was estimated as $C=C_{1}+$ $C_{2}+C_{3}+C_{4}+C_{5}+C_{6}$ with $C_{1}$ to $C_{6}$ being the respective costs for forwarding to roadside, chipping at roadside, hauling the comminuted material to the plant, administrative costs, reimbursement to land owners, and allocation costs for forwarders and chippers (Table 2). $C_{1}$ to $C_{6}$ were calculated for the NFI plots in the vicinity of each plant site according to the previously described procedure [21]. The hauling distances $d_{t}$ were calculated as the shortest distance from the plot to the plant site, multiplied by a winding factor of 1.3 .

3.4. Drying and Refining. For all three plants, it was assumed that excess combustion capacity could be used when available and that the only additional expense incurred by the plant was the cost of the extra raw material required to generate the heat needed for drying. The heat demand (see Section 3.2) was assumed to have a seasonal distribution according to a generic duration curve, as detailed data on duration were not available [37]. This results in an uncertainty in the time available for drying, and thus of the required drying power and the investment needed in drying equipment. At Lycksele, it was assumed that the increased combustion needed to generate heat for the dryer in seasons when the plant was not operating at capacity was also used to increase electricity production. The amount of additional electricity produced was estimated from the temperature and pressure of the steam (87.9 bar above atmospheric pressure and $504^{\circ} \mathrm{C}$, resp.). It was further assumed that at the Lycksele site, heat for the dryer was obtained by extracting steam from the turbine at the two pressures 1.9 bar total pressure and 0.4 bar and mixing them to obtain a temperature of $110^{\circ} \mathrm{C}$. For all three plants, an annual solid fuel production of 15000 $\mathrm{OD} t$ was assumed. As the same raw material was used, the differences between the fuels which are relevant to this study concern particle size and bulk density (Table 1).

The chosen drying device was a bed dryer, for which a drying temperature of $95^{\circ} \mathrm{C}$ would be sufficient. The MC of the raw material was assumed to be $50 \%$ wt and that of the dried material was assumed to be $10 \% \mathrm{wt}$. The operating parameters for the process were assumed to be the same as those for a low-temperature drying process used in a pellet plant at Grums, Sweden. The amount of heat required for drying was 1.67 times the drying enthalpy of the moisture evaporated [38]. Due to the relatively small scale of the hypothetical setup, recovery of the latent heat in the steam was not considered. The production options for the sites were summarized in Table 3.

3.5. Prices. The price of electricity was set at the average value for 2009 on the Nordpool spot market $\left(51.3 \$ \mathrm{MWh}^{-1}\right)$ and was converted into USD using the 2009 exchange rate of 7.65 SEK USD $^{-1}[39,40]$. The Lycksele plant received public support for producing green electricity, yielding an income of USD 38.3 $\mathrm{MWh}^{-1}$ [41]. As the cost data in [34] were in 2004 Euros, they were converted into SEK at a rate of 9.13 SEK $€^{-1}$ and then converted into today prices using the official consumer price index $[40,42]$.

3.6. Financial Assumptions. When calculating capital costs, an interest rate of $7 \%$ and a depreciation time of 15 years 
TABLE 3: Overview of current heat and electricity production for the three sites and the three production options: default (no dried fuel produced), pellet production (10\% MC), and pellet chip production (15\% MC).

\begin{tabular}{|c|c|c|c|c|c|c|c|c|c|}
\hline & \multicolumn{3}{|c|}{ Lycksele } & \multicolumn{3}{|c|}{ Vilhelmina } & \multicolumn{3}{|c|}{ Vännäs } \\
\hline & Default & Pellet & Pellet chips & Default & Pellet & Pellet chips & Default & Pellet & Pellet chips \\
\hline Heat delivered $\left(G W h\right.$ year $\left.^{-1}\right)$ & 99.4 & 99.4 & 99.4 & 58.5 & 58.5 & 58.5 & 39.0 & 39.0 & 39.0 \\
\hline Electricity production $\left(\mathrm{GWh}\right.$ year $\left.^{-1}\right)$ & 52.5 & - & - & 0 & 0 & 0 & 0 & 0 & 0 \\
\hline Fuel and heating water consumption (GWh year $\left.{ }^{-1}\right)$ & 227.6 & - & - & 75.1 & - & - & 42.2 & - & - \\
\hline
\end{tabular}

were assumed, resulting in an annuity factor of 0.110 . As a rough estimate, fixed operating and management costs were assumed to be $2 \%$ of the total value of the investment annually.

3.7. Investments. The major investment required to produce pellet chips is a dryer. Fuel pellet production requires a dryer and also a grinder and a pelletizer with a cooler. The costs of these investments were assigned by scaling the values reported in the data sources by a factor of 0.7 (Table 4).

Investment costs were estimated on the basis of data for a bed dryer installed at Gruvön [38] and a preceding study on pellet production [34]. For all three heating plants, it was assumed that the existing combustion capacity was sufficient for fuel drying and that no additional investment was needed. However, the sites had different drying capacities. Indirect costs (notably, for the construction of buildings for fuel handling and storage) were assumed to amount to $37 \%$ of the costs for the dryer, grinder, and pelletizing equipment [34]. It was further assumed that the dried fuel could be stored in sufficient quantities for continuous operation of the grinding, pelletizing, and cooling equipment and that little excess capacity was needed for either of these items.

3.8. Costs of Operations, Management, and Electricity. The fixed operating and management costs were assumed to be $10 \%$ of the value of the investment for the hammer mills and pelletizing equipment due to high wear, and $2 \%$ of the investment for the other equipment $[32,34]$. The variable operating and management costs for raw material handling, operating the chippers and dryers, and handling and packaging the finished fuel were set to $8.10 \$ \mathrm{OD} \mathrm{t}^{-1}$. The electricity consumption for grinding and pelletizing was set to $92 \mathrm{kWh} \mathrm{t}^{-1}$ of pellets [34]. For the bed dryer, an electricity consumption of $37.8 \mathrm{kWh} \mathrm{kg}^{-1}$ of moisture evaporated was assumed [38].

3.9. Transport Costs. To compare the distances over which the finished fuel would have to be transported to customers for the three sites, the geographical distributions of the relevant regional markets were estimated. Three market segments were considered:(1) small- and medium-scale district-heating plants using pellets or briquettes; (2) public buildings using heating oil; (3) other users of heating oil (excluding industrial, agricultural, forestry, and residential uses). For segments (2) and (3), it was assumed that the oil was primarily used for space heating and that there were no technical obstacles to replacing the oil burners with pellet burners. Residential uses were not considered because the bark and foliage contents of logging residues would be likely to cause dust problems on that scale.

Transport distances to small- and medium-scale district heating plants within a radius of $250 \mathrm{~km}$ from each site were computed on a digital map [43]. The cumulative transport distances were estimated independently for each of the sites. It was assumed that $50 \%$ of the pellets/briquettes combusted in each district heating plant could be supplied by a single site and that $10 \%$ of the oil consumed by segments (2) and (3) could be converted to biomass combustion using fuel supplied by the same site. The consumption data used were for 2009 [44].

It was assumed that pellets would be transported using dedicated bulk transport trucks with a maximum payload of 37.5 t (10\% MC). For pellet chip transport, general-purpose bulk trucks with a volume of $135 \mathrm{~m}^{3}$ were assumed. The bulk densities of pellets and pellet chips were assumed to be $0.33 \mathrm{t} \mathrm{m}^{-3}$ for fresh pellet chips ( $\left.50 \% \mathrm{MC}\right), 0.19 \mathrm{t} \mathrm{m}^{-3}$ for dried pellet chips (15\% MC), and $0.68 \mathrm{t} \mathrm{m}^{-3}$ for pellets (at $10 \% \mathrm{MC}$ ) [33]. Consequently, the transport cost for pellets was $65 \%$ of the production cost for pellet chips. Differences in costs for different types of trucks were not considered. The transport cost $\left(\$ \mathrm{t}^{-1} \mathrm{~km}^{-1}\right)$ for dried pellet chips was assumed to be identical to the previously discussed raw material transport cost, with the difference that exact data on the road distance were available, making the use of a winding factor unnecessary.

\section{Results}

4.1. Raw Material Supply. For each of the three plant sites, the total amounts of logging residues required to produce $15000 \mathrm{ODt}$ of either fuel pellets or pellet chips were calculated (Table 5).

4.2. Production Processes. At all three sites, it was assumed that additional logging residues would be combusted in the existing heating plants to generate heat for drying (Figure 1). Some of this energy was stored, in that it increased the heating value of the solid fuel produced for sale. In the case of Lycksele, some of this heat was also used to increase the plant net electricity production (by about $6 \%$ with pelletization and $8 \%$ without). The rest of the energy from the additional combustion was lost as low-temperature heat, either from the dryer or from the smokestack of the heating plant.

4.3. Costs for Production and Transport to Users. The transport costs from the Vilhelmina plant were significantly 
TABLE 4: Required investments for each of the three plants.

\begin{tabular}{|c|c|c|c|c|c|c|}
\hline & \multicolumn{2}{|c|}{ Lycksele } & \multicolumn{2}{|c|}{ Vilhelmina } & \multicolumn{2}{|c|}{ Vännäs } \\
\hline & Pellet & Pellet chips & Pellet & Pellet chips & Pellet & Pellet chips \\
\hline \multicolumn{7}{|l|}{ Dryer } \\
\hline Reference cost (million US\$) & 2.35 & 2.35 & 2.35 & 2.35 & 2.35 & 2.35 \\
\hline Reference steam capacity $\left(\mathrm{t} \mathrm{h}^{-1}\right)$ & 8.72 & 8.72 & 8.72 & 8.72 & 8.72 & 8.72 \\
\hline Steam capacity $\left(\mathrm{t} \mathrm{h}^{-1}\right)$ & 2.67 & 2.67 & 3.09 & 3.09 & 5.22 & 5.22 \\
\hline Investment (million US\$) & 1.03 & 1.03 & 1.14 & 1.14 & 1.01 & 1.01 \\
\hline \multicolumn{7}{|l|}{ Hammer mill } \\
\hline Reference cost (million US\$) & 0.079 & 0.079 & 0.079 & 0.079 & 0.079 & 0.079 \\
\hline Reference capacity (1000 t year ${ }^{-1}$ ) & 3.00 & 3.00 & 3.00 & 3.00 & 3.00 & 3.00 \\
\hline Capacity $\left(\right.$ t year $\left.^{-1}\right)$ & 2.14 & 0.00 & 2.14 & 0.00 & 2.14 & 0.00 \\
\hline Investment (million US\$) & 0.06 & 0.00 & 0.06 & 0.00 & 0.06 & 0.00 \\
\hline \multicolumn{7}{|l|}{ Pelletizing, cooling equipment } \\
\hline Reference cost, million US\$ & 0.76 & 0.76 & 0.76 & 0.76 & 0.76 & 0.76 \\
\hline Reference capacity $\left(\mathrm{th}^{-1}\right)$ & 9.00 & 9.00 & 9.00 & 9.00 & 9.00 & 9.00 \\
\hline Capacity $\left(\mathrm{th}^{-1}\right)$ & 2.14 & 0.00 & 2.14 & 0.00 & 2.14 & 0.00 \\
\hline Investment (million US\$) & 0.28 & 0.00 & 0.28 & 0.00 & 0.28 & 0.00 \\
\hline Investments, process equipment (million US\$) & 1.37 & 1.03 & 1.14 & 0.79 & 1.35 & 1.01 \\
\hline Indirect costs $(37 \%)$ & 0.51 & 0.38 & 0.42 & 0.29 & 0.50 & 0.37 \\
\hline Total costs (million US\$) & 1.87 & 1.41 & 1.56 & 1.09 & 1.85 & 1.38 \\
\hline
\end{tabular}

TABLE 5: Amount of logging residues required, average hauling distance $(\mathrm{km})$, and average cost for logging residue provision $\left(\$ O D \mathrm{t}^{-1}\right)$ for the production of $15000 \mathrm{OD}$ t of either fuel pellets or pellet chips.

\begin{tabular}{lccc}
\hline Plant site & Total amount of logging residues $\left(\mathrm{OD} \mathrm{t} \mathrm{yr}^{-1}\right)$ & Average hauling distance $(\mathrm{km})$ & ${\text { Resulting average cost }\left(\$ O D \mathrm{O}^{-1}\right)}$ \\
\hline Lycksele & 44000 & 18 & 100 \\
Vilhelmina & 20000 & 27 & 98.6 \\
Vännäs & 20000 & 21 & 93.7 \\
\hline
\end{tabular}

higher than those for the other two sites (Figure 2). The presence of a substantial market in close proximity to Vännäs resulted in a low initial transport cost for this site, although the difference compared to Lycksele was smaller for higher production capacities.

Production costs were the highest at the Vännäs site (Figure 2). This was primarily due to the relatively low capacity of its existing heat plant, which would mean that drying heat could only be produced during a shorter part of the year compared to the other sites. Consequently, handling the quantity of logging residues considered in this study would necessitate a relatively large drying capacity, resulting in higher costs. At Lycksele, the increased electricity production improved the profitability of the operation. It was relatively expensive to extract and transport raw material to the Vilhelmina plant because it is in a region that has a low average temperature and therefore has a comparatively low productivity per hectare.

The cost of transporting fuel to consumers from Vilhelmina was considerably greater than the average, while that for Vännäs was considerably lower than the average. For all three sites, the difference between the total costs for pellets and pellet chips were small. The only site at which pellets were the most profitable option was Vilhelmina. However, the relative influence of the various costs differed from site to site, with transport costs generally having a greater impact for pellet chips.

4.4. Sensitivity Analysis. It was apparent that the total cost was most sensitive to the raw material cost (Figure 3 ), with the production cost being less important. The raw material costs could be reduced in various ways, for example, by adopting improved technologies for early thinning, handling of logging residues, and stump extraction. The raw material cost would increase if stem wood was used, although this could potentially yield a more valuable final product.

The production costs were quite sensitive to the financial assumptions A lower rate of interest, for example, 5\%, and a longer depreciation time, for example, 25 years rather than 15 , would reduce capital costs by $35.4 \%$, reducing the production cost by 18 to $20 \%$. Such a low interest rate may be relevant for public policy considerations. Conversely, investments by private companies may require interest rates well over the assumed $7 \%$. 


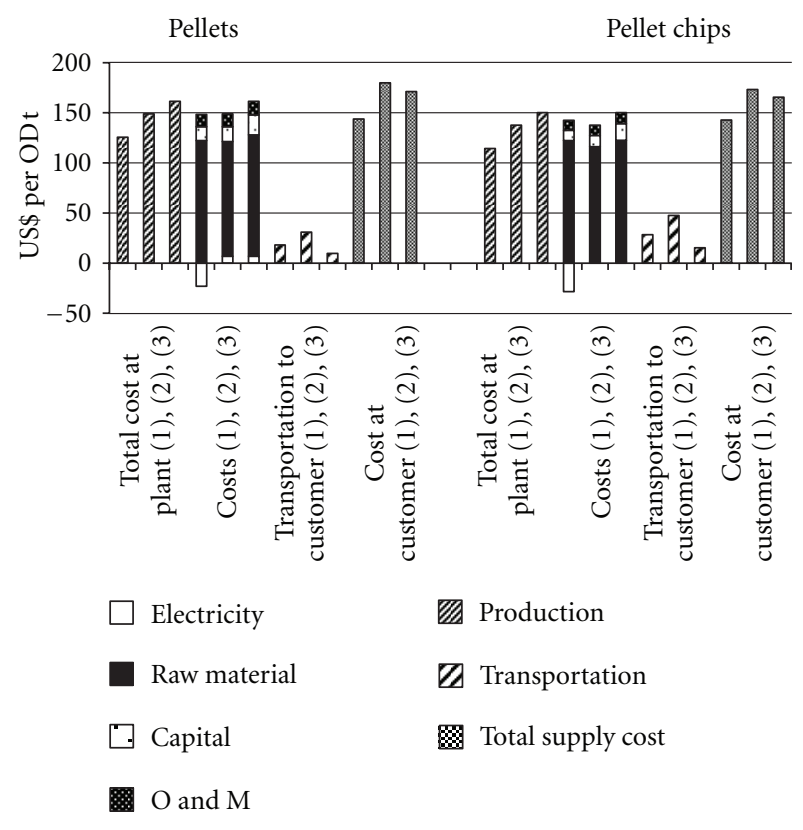

FIGURE 2: Supply costs for pellets (left) and pellet chips (right) when produced at (1) Lycksele, (2) Vilhelmina, and (3) Vännäs. Each plant was assumed to have a capacity of 15000 oven-dry tonnes $(\mathrm{OD} \mathrm{t})$, with logging residues used as the raw material.

\section{Discussion}

Pellet chip production would only be economically viable if their market price exceeded their total production and transport costs of $140-185 \$ \mathrm{OD} \mathrm{t}^{-1}\left(26.7-35.2 \$ \mathrm{MWh}^{-1}\right)$. For comparative purposes, the price for pellets used in mediumscale heat plants is around $216 \$ \mathrm{ODt}^{-1}\left(41.3 \$ \mathrm{MWh}^{-1}\right)$ [45]. It should be noted that the estimates discussed in this paper cover the costs of all operations from harvesting to delivery, with no analysis of how any profit would be distributed among different actors (such as the forestry, transport, and energy companies involved).

5.1. Harvesting and Transport of Raw Material. In this work, chipped logging residues were used both as a fuel for heat and power generation and as a raw material for manufacturing pellets and pellet chips. The supply cost of chipped logging residues proved to be the most important component in the production cost of pellets and pellet chips. It is known from the literature that the costs of procuring raw materials significantly affect the profitability of production [34]. Raw materials with lower bark and needle contents are likely to be more expensive than logging residues. For example, the reported price of chipped energy wood at the roadside was $98 \$ \mathrm{t}^{-1}$, compared to $85 \$ \mathrm{t}^{-1}$ for chipped logging residues [46]. On the other hand, if a product with lower ash concentrations is produced, the market price of refined fuel for the small-scale market is considerably higher than the prices offered by operators of district heating plants (the price offered for pellets by small-scale residential users was about $280-390 \$ \mathrm{OD} \mathrm{t}^{-1}$ in 2009) $[45,47]$. Identifying the most profitable process therefore necessitates a compromise. Cheaper raw materials such as whole trees, tree sections, and logging residues tend to be more ash-rich and yield a lowervalue product, while more expensive raw materials with less bark and foliage yield high-value products.

There is great potential for increasing the cost-effectiveness of the harvesting and forwarding of logging residues, stumps, and wood from precommercial thinnings, since the technologies used at present are far from mature. Another possibility would be to reduce the amounts of needles, leaves, and bark in cheaper wood assortments, for example, through storage before chipping or mechanical separation before or after chipping. Several methods have been demonstrated for removing foliage, including separation using screens $[48,49]$ and aerodynamic methods [50].

5.2. Plant Capacity, Plant Location, and Production Cost. The production cost (excluding raw material and transport costs) for pellet chips was 8.4 to $10.1 \%$ lower than that for pellets. This was primarily due to lower capital costs, lower maintenance costs for high-wear equipment (pellet chip production does not require grinding and pelletizing equipment), and lower electricity consumption. The total cost for producing and transporting pellet chips was slightly lower than that for pellets at all sites other than Vilhelmina, which is relatively distant from its markets. It was observed that for lower production capacities and shorter average transport distances (the Lycksele and Vännäs cases), the reduced production cost of pellet chips was more important than their higher road transport costs compared to pellets. For higher production capacities and longer average transport distance (the Vilhelmina case), transport costs became more important, making pellets more competitive.

Drying is the most important plant operation in terms of production costs because it requires large amounts of heat and electricity. Recovering heat from the dryer by condensing the steam could potentially make the process more economical, especially on larger scales. Another way to reduce the heat load would be to allow the biomass to drying during storage. This could be done before comminution, after coarse comminution (e.g., chunking), which result in good storage properties [51-53] or after chipping. The use of low-temperature drying systems [54] could conceivably also reduce drying costs and make small-scale production more economical, reducing average transport distances. If drying could be conducted in modified cargo containers, handling costs would be minimized, reducing operational costs. Drying at small-scale district heating plants, as suggested by Yrjölä [27], would also reduce costs as no central drying location would be needed. However, more information is needed on the costs of drying systems of the type studied by Yriölä. More detailed information will be required to accurately assess the scope for integrating fuel drying into existing district heating plants. Important factors include the plant annual excess heating capacity, the length of time during which this excess heat is available, and the existing infrastructure for processes such as fuel handling. The nature of the plant local markets also has a significant impact. 


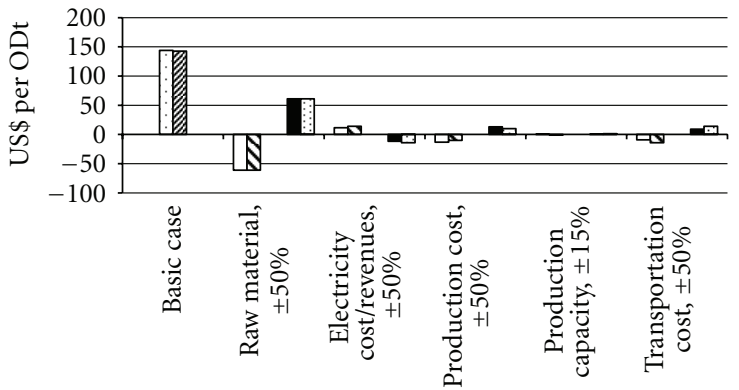

(a)

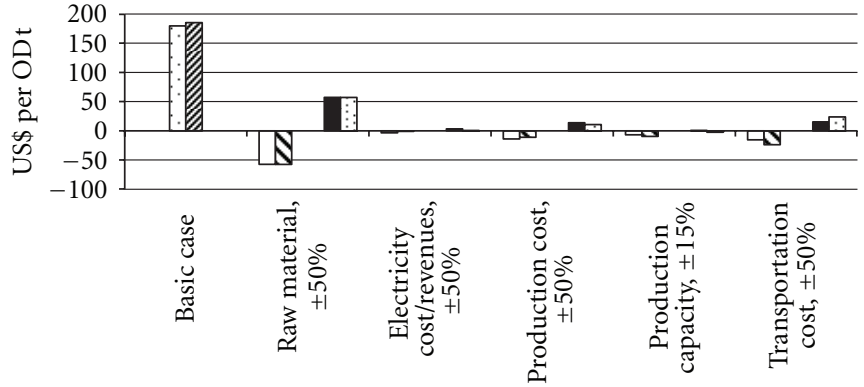

(b)

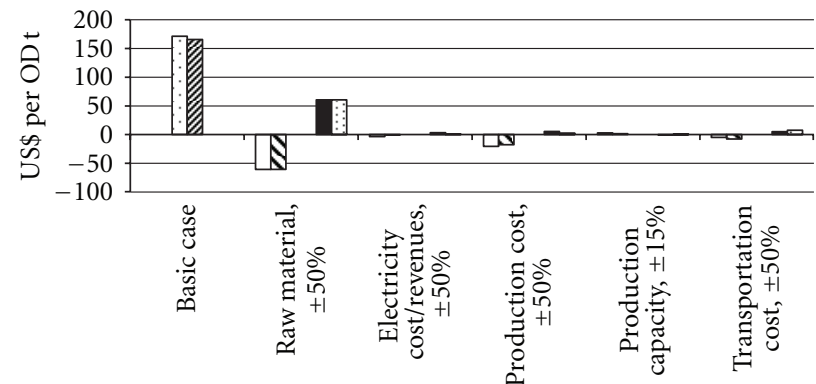

Pellets, low parameter value

Pellets, high parameter value

Pellet chips, basic case

$\square$ Pellets, basic case

$\mathbf{\Delta}$ Pellet chips, low parameter value $\square$ Pellet chips, high parameter value

(c)

Figure 3: Results of the sensitivity analysis for the three plant sites_Lycksele (a), Vilhelmina (b), and Vännäs (c)—for pellet production (1) and pellet chip production (2). The following parameters were varied: raw material cost, electricity cost/electricity revenues, production cost, transport costs and product price $( \pm 50 \%)$, and productive capacity $( \pm 15 \%)$.

It is important to exploit existing combustion capacity rather than having to invest in new combustors. When existing generating capacity is available, the use of drying heat for electricity generation greatly reduces net production costs. Increasing the annual utilization time for the drying equipment reduces the investment needed for a given amount of dried material. If less heat is needed for drying, the utilization time for the dryer can be increased for a given duration curve, further reducing the dimensions of the dryer.

The heat load would also be reduced if slightly higher MC in the product could be accepted. Drying to 15\% MC (below fiber saturation and sufficient to prevent the deterioration of the pellet chips by biological processes [55]) would reduce the need for drying heat by about $7 \%$ and would thus reduce the quantity of fuel consumed by the plant. This would make it possible to use a smaller dryer and less heat, which would reduce production costs and also increase the dryer annual utilization time. For Vilhelmina and Vännäs, the net effect of producing a fuel with a $15 \% \mathrm{MC}$ would be to reduce production costs by $2-3 \%$ relative to those incurred at $10 \%$ MC (25.9-26.2 \$ $\mathrm{MWh}^{-1}$ rather than 26.2-26.6\$ $\left.\mathrm{MWh}^{-1}\right)$.

However, at Lycksele, the reduced demand for drying heat would reduce the amount of electricity generated, with the net result that increasing the MC of the fuel would not be profitable. For the other two sites, increasing the MC of the fuel would increase the number of potential locations for the dryer because smaller dryers can be operated with smaller sources of excess heat. An MC of $15 \%$ can be achieved with a simpler drying process and a cooler heat source compared to those required for an $\mathrm{MC}$ of $10 \%$. These factors could increase the cost savings for producing fuel with an MC of $15 \%$ well beyond the $2-4 \%$ mentioned above. If a sufficient number of users have some drying capacity, or if small-scale flue gas condensation equipments were to become widely available at low cost, this result could be further improved.

While the economic yields of pellet production and pellet chip production are similar, an important difference is that dispensing with grinding and pelletization reduces the minimum investment required by 25 to $35 \%$, if the assumptions made in this work hold. Provided that a market exists, risk-averse producers (who are likely to demand rates of return on invested capital that are substantially greater than 7\%) may therefore find it preferable to manufacture pellet chips rather than pellets. The simpler production process for pellet chips would also reduce the risk of the enterprise and the amount of specialized know-how needed for production.

5.3. End Market and Product Transport. For the production scale considered in this study, the different transport properties of pellets and pellet chips were of limited importance. 
There were two reasons for this. First, the transport cost was only $12.6-25.4 \%$ of the total cost for the delivered product. Second, limitations on the maximum weight of the trucks payloads mean that the higher bulk density of pellets cannot be fully exploited. Under the assumed conditions, the lower production costs for pellet chips compensated for this difference. One option that was not considered is increasing the bulk density of chips through compression. It has been reported that applying a pressure of $0.3 \mathrm{MPa}$ to green pine chips increased their density to $0.280 \mathrm{OD} \mathrm{t} \mathrm{m}^{-3}$, which is about 40\% higher than that without compression [56].

Only transportation by road was considered in this work. However, once the cargo has been loaded, rail transport is cheaper than road by a factor of 16 per $t$ and $\mathrm{km}$. For instance, at a loading cost of 4.3-5.7 $\$ \mathrm{t}^{-1}$, the road transport cost considered in this work would make reloading worthwhile for distances above a few tens of $\mathrm{km}$. Sea transportation has even lower marginal costs [57]. Thus, by using rail and sea transport, the range of markets available for a given location could be expanded significantly.

It was assumed that pellet chips could be fed into and burned in a significant proportion of existing medium- and small-scale combustors without modification or with only very slight modification. In cases where pellet chips could be sold to the small-scale market as well as the mediumscale market (which cannot be taken for granted, as smallscale equipment is more sensitive to fluctuations in feeding rate and operated by nonprofessionals) production could be more profitable. Better control technology may make the equipment less sensitive to fluctuations [28].

For pellet chips to be competitive with pellets, they would probably have to be significantly less expensive to buy. Lower cost of pellet chips compared to pellets would also be necessary to motivate consumers to convert existing oil- or electricity-based heating systems to use dried biomass fuels. Reducing the prices of pellet chips relative to pellets would make their production less profitable than the market price for pellets would suggest. The influence of price on demand was not considered in this work. It will be necessary to study the feeding and combustion properties of pellet chips in different types of equipment to identify any modifications needed to cope with the differences in fuel properties. Equipment manufacturers would have an important role to play in any such work. It will also be important to examine how demand is affected by fuel price and the different properties of pellet chips compared to pellets in order to accurately estimate the market price of the refined fuel. The increased market size accessible via sea and rail transportation should also be investigated, focusing on communities such as those along the interior railways in northern Sweden.

\section{Conclusions}

The supply costs (including raw material and transport costs) for producing $15000 \mathrm{OD}$ t of either wood pellets or small dried wood chips (pellet chips) annually have been estimated for three sites in Northern Sweden. The estimated cost of pellet production is $144-176 \$ \mathrm{OD} \mathrm{t}^{-1}\left(27.4-33.5 \$ \mathrm{MWh}^{-1}\right)$ while that of pellet chips is $143-173$ \$OD t ${ }^{-1}$ (27.233.0 $\left.\$ \mathrm{MWh}^{-1}\right)$. Assuming that the products can be sold at a price of $216 \$ \mathrm{ODt}^{-1}\left(41.3 \$ \mathrm{MWh}^{-1}\right.$, the current price for refined fuels used in heating plants in northern Sweden [46]) pellet chip production should be economically viable under the circumstances considered. For plants with low production capacities, pellet chips are expected to be more economical than pellets because their reduced production costs outweigh their greater road transport costs. The opposite is true for sites with greater productive capacities that are more distant from their markets. The capital costs for pellet chips were $17-27 \%$ lower than those for pellets, making pellet chip production more attractive to risk-averse producers.

The estimated costs for harvesting, forwarding, chipping, and transporting logging residues (including the cost of the additional fuel burned in the energy plant) were 114$122 \$ \mathrm{OD} \mathrm{t}^{-1}$ of fuel produced, making the raw material cost the most important component of the total cost of production and transportation. Raw material costs could be substantially reduced by developing improved methods for thinning and stump harvesting operations.

If the practical issues can be solved, it would be far more profitable to produce fuel for small-scale residential heating, which is much more expensive than that for mediumscale applications (the price of small-scale fuel is 390$410 \$ \mathrm{OD} \mathrm{t}^{-1}$, compared to about $240 \$ \mathrm{OD} \mathrm{t}^{-1}$ for mediumscale). This is true even though the raw materials for smallscale fuel production (which include e.g., wood from early thinnings) are more expensive because of the need for low particle emissions. Cost-effective processes for foliage and bark separation could make it possible to cater to this market using cheaper raw materials (e.g., logging residues from regeneration fellings).

Improved methods for compacting and transporting chips could shift this market niche towards larger production capacities. Further development of small-scale low-temperature drying techniques would reduce the optimum process capacity, improving the competitiveness of pellet chips. To quantify the size of the market for pellet chips, it will be necessary to study the feeding and combustion properties of equipment designed for use with pellets and to determine how they would have to be modified for use with pellet chips. In particular, it will probably be necessary to increase their fuel feeding volume flows to compensate for the lower bulk density of pellet chips.

The feasibility of integrating fuel drying with existing combined heat and power plants and small-scale district heating plants should be studied in more detail, focusing on the specific circumstances at individual plants and sites. Important factors include the length of time during which excess heat is available, the properties of the steam generated, the potential drying capacity, and the availability of suitable raw material (energy wood from early thinning in particular). Storage of raw materials prior to comminution and drying should be investigated as a means of reducing their MC and the abundance of alkali-rich needles and leaves. Finally, it will be important to identify every heat source that could be used for fuel drying at a given site; even less intense 
heat sources could potentially be used in low-temperature drying systems of the type described by Nordhagen [56].

\section{Acknowledgment}

Financial support by Kempestiftelsen is gratefully acknowledged.

\section{References}

[1] J. Heinimö and M. Junginger, "Production and trading of biomass for energy — an overview of the global status," Biomass \& Bioenergy, vol. 33, no. 9, pp. 1310-1320, 2009.

[2] M. Peksa-Blanchard, P. Dolzan, A. Grassi et al., "Global wood pellet markets and industry: policy drivers, market status and raw material potential," IEA Bioenergy Task 40, 2007.

[3] Pelletsindustrierna (Organization of Swedish pellet producers), 2010, http://www.pelletsindustrin.org/.

[4] Swedish District Heating Association, "Fuel and production 2009," 2012, http://www.svenskfjarrvarme.se/Statistik-Pris/ Fjarrvarme/Energitillforsel/.

[5] Statistics Sweden, "Energy statistics for one-and two-dwelling buildings in 2008," ES 2009:07, Stockholm, Sweden, 2009.

[6] E. K. Ackom, W. E. Mabee, and J. N. Saddler, "Industrial sustainability of competing wood energy options in Canada," Applied Biochemistry and Biotechnology, vol. 162, no. 8, pp. 2259-2272, 2010.

[7] A. Uasuf and G. Becker, "Wood pellets production costs and energy consumption under different framework conditions in Northeast Argentina," Biomass \& Bioenergy, vol. 35, no. 3, pp. 1357-1366, 2011.

[8] S. Chauhan, "Biomass resources assessment for power generation: a case study from Haryana state, India," Biomass \& Bioenergy, vol. 34, no. 9, pp. 1300-1308, 2010.

[9] M. Junginger, T. Bolkesjø, D. Bradley et al., "Developments in international bioenergy trade," Biomass \& Bioenergy, vol. 32, no. 8, pp. 717-729, 2008.

[10] M. C. Bolding and B. L. Lanford, "Wildfire fuel harvesting and resultant biomass utilization using a cut-to-length/small chipper system," Forest Products Journal, vol. 55, no. 12, pp. 181-189, 2005.

[11] D. G. Neary and E. J. Zieroth, "Forest bioenergy system to reduce the hazard of wildfires: white Mountains, Arizona," Biomass \& Bioenergy, vol. 31, no. 9, pp. 638-645, 2007.

[12] C. Rhén, "Chemical composition and gross calorific value of the above-ground biomass components of young picea abies," Scandinavian Journal of Forest Research, vol. 19, no. 1, pp. 7281, 2004.

[13] P. Rademacher, "Contents of nutrient elements in tree components of economically important species in relation to their residual utilisation," Holz als Roh-und Werkstoff, vol. 63, pp. 285-296, 2005.

[14] P. Krecl, Impact of residential wood combustion on urban air quality, Doctoral thesis, Stockholm University, Department of Applied Environmental Science, Stockholm, Sweden, 2008.

[15] A. Novaković, S. C. van Lith, F. J. Frandsen, P. A. Jensen, and L. B. Holgersen, "Release of potassium from the systems K-CaSi and K-Ca-P," Energy \& Fuels, vol. 23, no. 7, pp. 3423-3428, 2009.

[16] Swedish standard SS 187120, Biofuels and peat-Fuel pellets, Swedish Standards Institute, Stockholm, Sweden, 1998.

[17] L. Esteban, I. Mediavilla, M. Fernández, and J. Carrasco, "Influence of the size reduction of pine logging residues on the pelleting process and on the physical properties of pellets obtained," PELLETS 06, 2006.

[18] H. Örberg, M. Thyrel, G. Kalén, and S. Larsson, "Pelletizing and combustion of wood from thinnings, Swedish University of Agricultural Sciences," Report BTK 207:14, Biomass Technology and Chemistry, 2007.

[19] L. Martinsson and S. Österberg, "Pelletising using forest fuels and Salix as raw materials. A study of the pelletising properties," report 876, Värmeforsk, 2004.

[20] F. Wikström, "The potential of energy utilization from logging residues with regard to the availability of ashes," Biomass \& Bioenergy, vol. 31, no. 1, pp. 40-45, 2007.

[21] D. Athanassiadis, A. Lundström, and T. Nordfjell, "Procurement costs of slash and stumps in Sweden-a comparison between south and north Sweden," in Proceedings of the World Bioenergy, Jönköping, Sweden, May 2010.

[22] D. Athanassiadis, Y. Melin, A. Lundström, and T. Nordfjell, "Marginal cost for harvest of slash and stumps from regeneration fellings," Working paper 261, Swedish University of Agricultural Sciences, Department of Forest Resource Management, 2009.

[23] L. Beijbom and M. Nilsson, Chip Combustion for Farms and Small Residential Buildings, Silviconsult, Bjärred, Sweden, 1979.

[24] I. Obernberger, "Decentralized biomass combustion: state of the art and future development," Biomass \& Bioenergy, vol. 14, no. 1, pp. 33-56, 1998.

[25] J Yrjölä, Modelling and experimental study on wood chips boiler system with fuel drying and with different heat exchangers, Doctoral Dissertation, Helsinki University of Technology, Department of Mechanical Engineering, Laboratory of Applied Thermodynaimics, Espoo, Finland, 2006.

[26] S. vanLoo and J. Koppejan, Handbook of Biomass Combustion and Co-Firing, Earthscan, London, UK, 2008.

[27] J. Yrjölä, "Production of dry wood chips in connection with a district heating plant," Thermal Science, vol. 8, no. 2, pp. 143155, 2004.

[28] T. Korpela, T. Björkqvist, and P. Lautala, "Durable feedback control system for small scale wood chip combustion," in Proceedings of the World Bioenergy, Svebio, Jönköping, Sweden, 2008.

[29] C. Nati, R. Spinelli, and P. Fabbri, "Wood chips size distribution in relation to blade wear and screen use," Biomass \& Bioenergy, vol. 34, no. 5, pp. 583-587, 2010.

[30] J. Pedersen, "Stoker firing of pellet chips in small-scale pellet combustion equipment," AgroTech, Denmark, 2009, http:// www.landbrugsinfo.dk/ByggeriFiler/FT_MAS_102_Pilleflis.pdf.

[31] R. Abdallah, S. Auchet, and P. J. Méausoone, "Experimental study about the effects of disc chipper settings on the distribution of wood chip size," Biomass \& Bioenergy, vol. 35, no. 2, pp. 843-852, 2011.

[32] S. Mani, S. Sokhansanj, X. Bi, and A. Turhollow, "Economics of producing fuel pellets from biomass," Applied Engineering in Agriculture, vol. 22, no. 3, pp. 421-426, 2006.

[33] G. Eriksson, C. Boman, U. Bergsten, and D. Bergström, "Fuel characterization of pellet chips," Forest Products Journal, vol. 61, no. 2, pp. 143-148, 2011.

[34] G. Thek and I. Obernberger, "Wood pellet production costs under Austrian and in comparison to Swedish framework conditions," Biomass \& Bioenergy, vol. 27, no. 6, pp. 671-693, 2004.

[35] K. O. Lindblad, "Personal communication," June 10, 2010.

[36] E. Kjellson, Eon Sverige AB, personal communication, 2010. 
[37] G. Bergendahl, "Investing in combined heat and powereconomic and environmental benefits," report FE 2008-413, University of Gothenburg, Department of Business Administration, Göteborg, Sweden, 2008.

[38] S. Olsson, Stora Enso, Grums, Sweden, personal communication 2010

[39] Nordpool, elspot prices, 2011, http://www.nordpoolspot.com/ Market-data1/Elspot/Area-Prices/ALL1/Hourly/.

[40] Sveriges Riksbank, Average exchange rates 2004 and 2009, 2012, http://www.riksbank.se/sv/Rantor-och-valutakurser/.

[41] Svenska Kraftnät (the Swedish national grid), "Marknadsstatistik för elcertifikatssystemet,” 2011, https://elcertifikat.svk .se/cmcall.asp.

[42] Statistics Sweden, Consumer price index, 2011, http://www .scb.se/Pages/TableAndChart__-_272151.aspx.

[43] Eniro, 2011, http://www.eniro.se/.

[44] Statistics Sweden, "Kommunal och regional energistatistik," 2011, http://www.scb.se/Pages/Product_--_24622.aspx.

[45] Pelletsindustrierna (Organization of Swedish pellet producers), 2010, http://www.pelletsindustrin.se/.

[46] Association of Northern Forest Owners (Norra Skogsägarna), Price list 158E 05, Umeå, interior region, 2010, http://www .norraskogsagarna.se/templates/Page.aspx?id=1073.

[47] Swedish Energy Agency, Price information sheet for biofuels, peat etc, No 3, 2010, http://www.energimyndigheten.se/.

[48] U. Eriksson and L. Moberg, "A simple method for separating fines from fuel chips," Research Notes No 224, Swedish University of Agricultural Sciences, Faculty of Forestry, Department of Operational Efficiency, 1991.

[49] J. A. Sturos, "Segregation of foliage from chipped tree tops and limbs," Research Note No. NC-146, North Central Forest Experiment Station, USDA Forest Service, Saint Paul, Minn, USA, 1973.

[50] T. Persson and Y. Stade, Sortering av helträdsflis och hyggesavfallsflis, vol. 26 of $P H U$ rapport, Project Whole-tree Utilization, Stockholm, Sweden, 1976.

[51] E. F. Kristensen, P. D. Kofman, and P. D. Jensen, "Counter pressure on ventilation of different types of wood chip and chunkwood," Biomass \& Bioenergy, vol. 25, no. 4, pp. 399-408, 2003.

[52] V. Scholz, C. Idler, W. Daries, and J. Egert, "Development of mould and losses during storage of wood chips," Holz als Rohund Werkstoff, vol. 63, no. 6, pp. 449-455, 2005.

[53] J. Nurmi, Polttohakkeen kuivatus traktorikonteissa, vol. 687 of Folia Forestalia, 2007.

[54] E. Nordhagen, "The drying of wood chips with two hydroelectric plants in Norway," in Proceedings of the 44th International Symposium on Forestry Mechanization (FORMEC '11), Rein, Austria, October 2011.

[55] B. Strömberg, "Fuel Handbook," report 911, Värmeforsk, Stockholm, Sweden, 2005.

[56] C. Angus-Hankin, B. Stokes, and A. Twaddle, "The transportation of fuelwood from forest to facility," Biomass \& Bioenergy, vol. 9, no. 1-5, pp. 191-203, 1995.

[57] M. Forsberg, A. Baky, H. Westiln, D. Ljungberg, and P. Ytterberg, "Jordbruket som leverantör av åkerbränsle till storskaliga kraftvärmeverk,” JTI-report Lantbruk \& Industri 361, Swedish Institute of Agricultural and Environmental Engineering, 2007. 

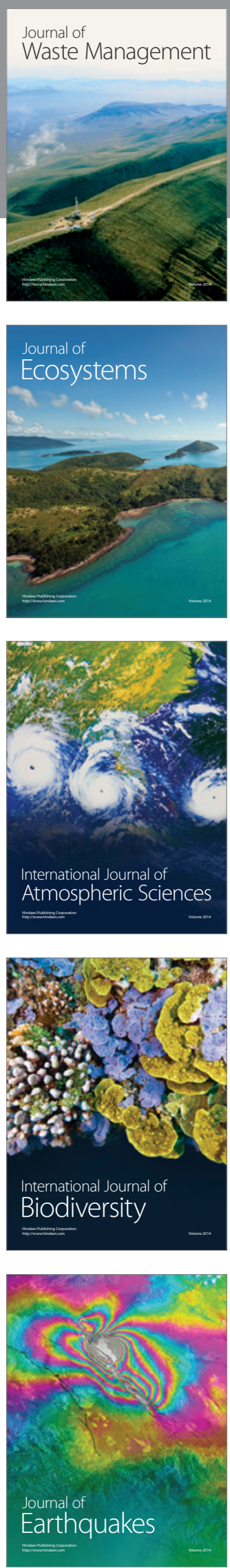
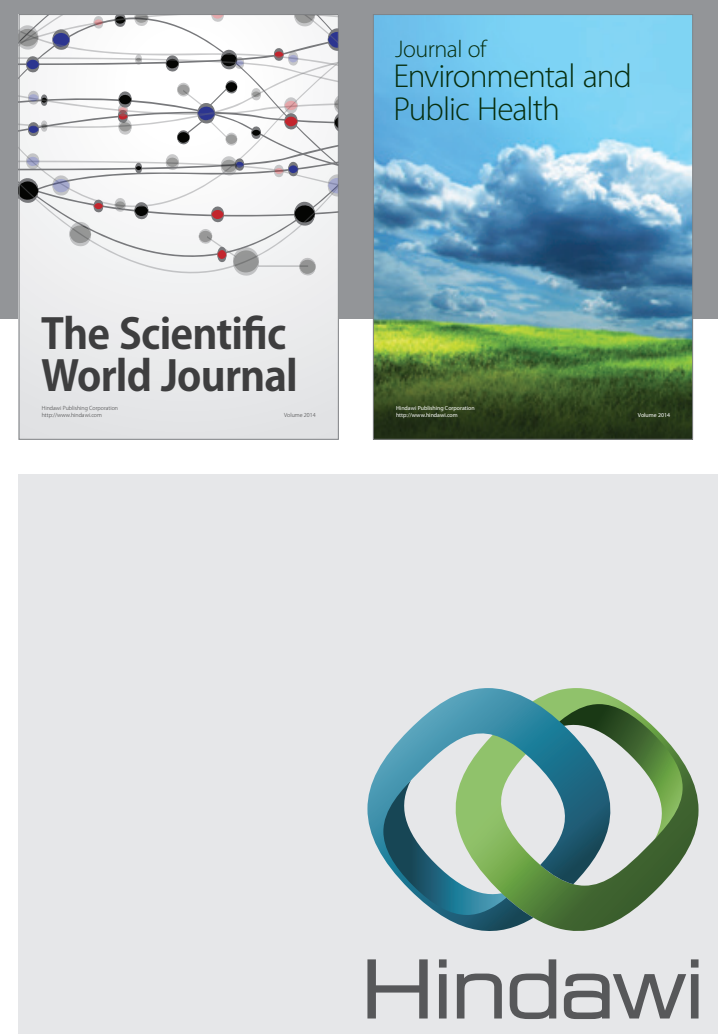

Submit your manuscripts at

http://www.hindawi.com
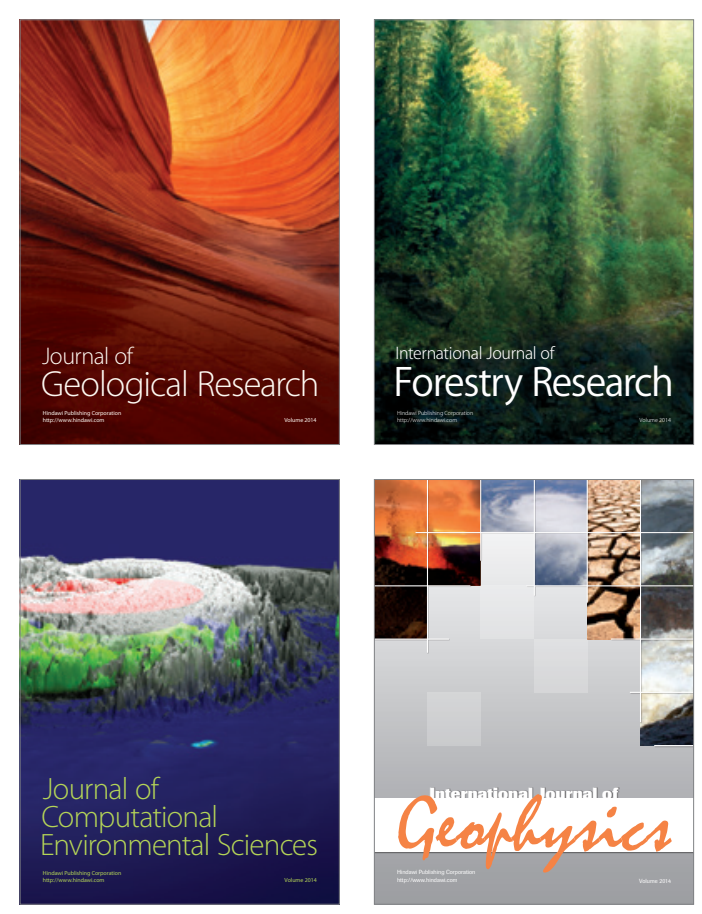
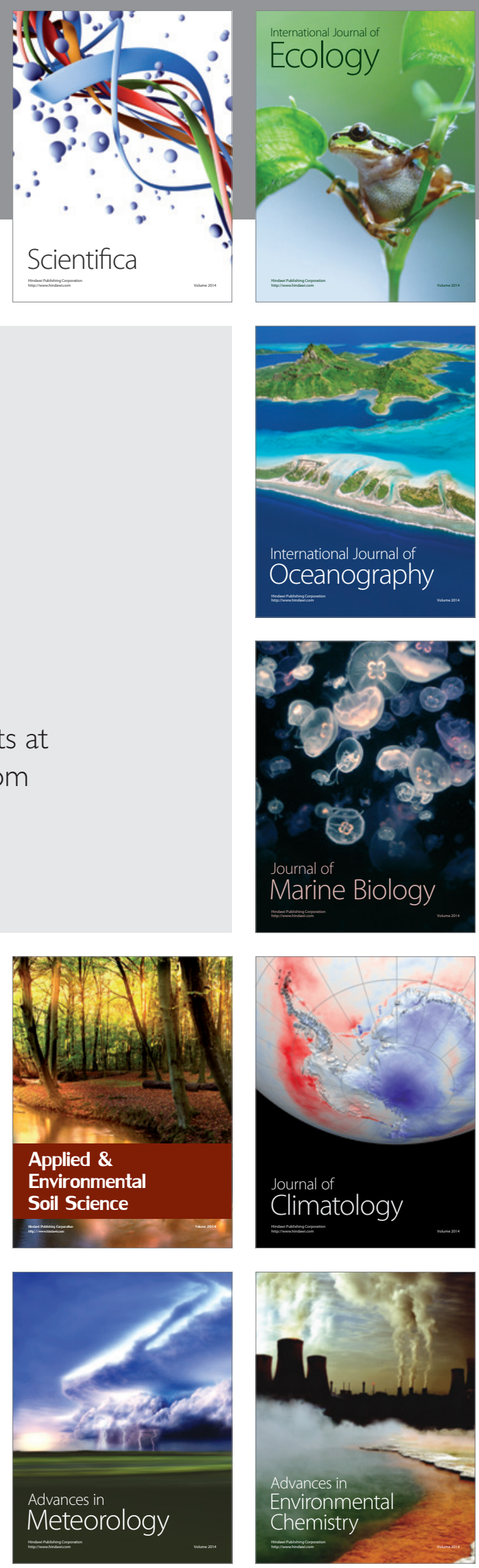